\title{
PESCARIAS MULTI-ESPECÍFICAS NA REGIÃO DA FOZ DO RIO DOCE, ES, BRASIL: CARACTERÍSTICAS, PROBLEMAS E OPÇÕES PARA UM FUTURO SUSTENTÁVEL
}

\author{
PINHEIRO, H.T.* \& JOYEUX, J.-C \\ Departamento de Ecologia e Recursos Naturais, Universidade Federal do Espírito Santo \\ Av. Fernando Ferrari, 514, Goiabeiras, 29075-910, Vitória, ES, Brasil. \\ *Correspondência: htpinheiro@gmail.com
}

\begin{abstract}
Pinheiro, H.T., Joyeux, J.-C. 2007. Multispecific fisheries in the region of Doce River estuary, state of Espírito Santo, Brazil: Characteristics, problems and options for a sustainable future. Braz. J. Aquat. Sci. Technol. 11(2):15-23. ISSN 1808-7035. Fishing activities are an important component of the society and culture of Povoação, a small Brazilian city located on the northern shore of the Doce River, close to the sea and to many coastal lakes. Fishing arts and gears used are the seine, caceia (a controlled-drifting gill net), jequi (a type of trap or pot), hookand-line, hand net (dip net), gill net, beach net and cast net. Fishing is carried out for commerce, sport or subsistence. Commercial catches are sold to intermediate buyers. Coastal lakes hold the highest number of fishing methods, followed by rivers and sea. Sea fishing is the activity with the highest income, but is carried out by few fishermen, due to the dangers faced by the small rowing boats. Taking into account all fishing arts and all ecosystems in the area, the catches were composed of 63 fish species. Gillnets captured the highest number of species and the coastal lake Monsarás had the highest fish diversity. The local fishermen have a deep traditional knowledge of the dynamics of the resources they exploit. However, some features of fishing activities put at risk the sustainability of the catch. Environmental education, sustainable alternatives to predatory fishing activities, fisheries management and creation of areas either fully protected or for sustainable uses are possible options to guarantee the continuity and productivity of the species in the long term.
\end{abstract}

Key-words: traditional fisheries, estuarine and coastal fisheries, impacts, multiple gears; sustainability.

\section{INTRODUÇÃO}

Além da evidente relevância econômica, a pesca e as atividades associadas beneficiam as sociedades pelo seu importante componente social e cultural (Cowx \& Gerdeaux, 2004). Contudo, a falta de informação sobre a própria estrutura da pesca é um grande problema enfrentado pelo Brasil que dificulta a elaboração de planos e práticas para seu manejo sustentável (Boffo \& Reis, 2003).

Ambientes litorâneos, como lagunas e estuários são considerados altamente produtivos porém muito frágeis (Bazairi et al., 2003). Estes ecossistemas são também alvos de fortes pressões antrópicas, tanto por sistemas de produção pesqueira como pelo crescimento desordenado da população (Albaret \& Lae, 2003; Barros et al., 2000). Assim, pescarias multi-específicas localmente conduzidas com uma variedade de petrechos têm reduzido a produtividade, qualidade e funções destes ecossistemas como áreas de berçário, desova e alimentação (Vega-Cendeja \& Santillana, 2004; Bazairi et al., 2003). Devido à acelerada e insustentável demanda por peixes e recursos naturais, cada vez mais comunidades litorâneas têm reportado uma diminuição na qualidade e quantidade dos desembarques pesqueiros (Chaves et al., 2002; Rogers \& Beets, 2001).
Tomadores de decisão requerem informações de cunho biológico sobre os recursos vivos explorados, incluindo padrões migratórios, áreas e temporadas de reprodução e características do ciclo de vida das espécies envolvidas. Para desenvolver programas de conservação em um contexto de manejo integrado, é necessário o entendimento dos processos que afetam as funções ecológicas dos ecossistemas, incluindo a própria pesca (Rueda \& Defeo, 2003). Portanto, a preservação das espécies ou estoques requer conhecimentos tanto biológicos dos peixes quanto ambientais, sociais, econômicos e culturais dos pescadores (Cowx \& Gerdeaux, 2004). Eles entendem da dinâmica dos recursos pesqueiros utilizados, sendo o estoque diretamente relacionado ao petrecho e ao padrão espacial de exploração (Camargo \& Petrere, 2001; Mackinson \& Nottestad, 1998). Os conhecimentos dos próprios pescadores, tanto a respeito da abundância do recurso quanto dos impactos que eles mesmos geram, é um recurso primário de informação.

A comunidade de Povoação, Linhares, ES, vive na perspectiva de um importante aumento dos impactos antrópicos e de uma crescente demanda pelos recursos diretamente extraídos do ambiente. O crescimento acelerado da população local, puxado pelo desenvolvimento turístico e industrial (ambos incipientes, 
mas ambos desenfreados), ameaça destruir ou alterar as características socioculturais desta comunidade ainda tradicional. O presente trabalho portanto apresenta as artes de pesca e os atributos técnicos, biológicos e sócio-culturais das pescarias tradicionais realizadas em Povoação. A descrição dos atributos é baseada nos conhecimentos populares sobre as safras, os locais e os períodos de maturação das principais espécies capturadas nos ecossistemas da região. As informações providenciam uma base para o futuro desenvolvimento de projetos de conservação e planos de manejo para a área.

\section{MATERIAIS E MÉTODOS}

\section{Área de Estudo}

A vila de Povoação situa-se no município de Linhares (19³3'45"S; 3948'45"W), a $36 \mathrm{~km}$ da sede do município e $160 \mathrm{~km}$ ao norte de Vitória, capital do estado do Espírito Santo. A vila, de 29 ha de área e cerca de 1300 habitantes, localiza-se na margem norte do rio Doce, a $10 \mathrm{~km}$ de sua foz e a $1 \mathrm{~km}$ do mar (Fig. 1). O rio Doce, com $875 \mathrm{~km}$ de extensão, é responsável pelo regime de águas de toda a planície costeira. As praias são oceânicas, abertas e com forte batimento de ondas. A região se encontra numa zona de grande produtividade, pois é influenciada ao norte pelas águas oligotróficas tropicais da corrente do Brasil e ao sul por ressurgências costeiras sazonais (Schmid et al., 1995). As principais atividades econômicas da região são li- gadas à pesca, agricultura, educação e mais recentemente a uma indústria de petróleo e gás. Devido ao desenvolvimento industrial na região, é esperado para os próximos anos um grande aumento da população de Povoação.

\section{Coleta e Análise dos Dados}

O trecho de $40 \mathrm{~km}$ entre a foz do rio Doce, vila de Povoação, e a comunidade de Degredo, em Linhares, foi percorrido para levantar as atividades pesqueiras que são desenvolvidas nesta extensa área. $A$ freqüência de percurso foi diária entre outubro e dezembro 2004, e semanal entre janeiro e fevereiro 2005. A descrição das atividades de pesca e a coleta de informações sobre o conhecimento tradicional das capturas foram baseadas em entrevistas com 16 pescadores e membros da comunidade. As informações verbais foram analisadas qualitativamente. As entrevistas ocorreram na forma de conversas estruturadas, onde foram abordados assuntos relativos a atributos técnicos, biológicos e culturais. Segundo Mackinson \& Nottestad (1998) o modo mais eficaz de obter uma integração de conhecimentos é através da conversa. Este modo de avaliação se mostra efetivo devido à importância da comunicação corporal.

Vinte e sete pescarias (operações de pesca), de diversos tipos de petrechos e em vários ambientes, foram acompanhadas (Tabela 1). Os peixes marinhos capturados foram identificados segundo Figueiredo (1977), Fischer (1978), Figueiredo \& Menezes (1978; $1980 ; 2000)$, Menezes \& Figueiredo $(1980 ; 1985)$. Os

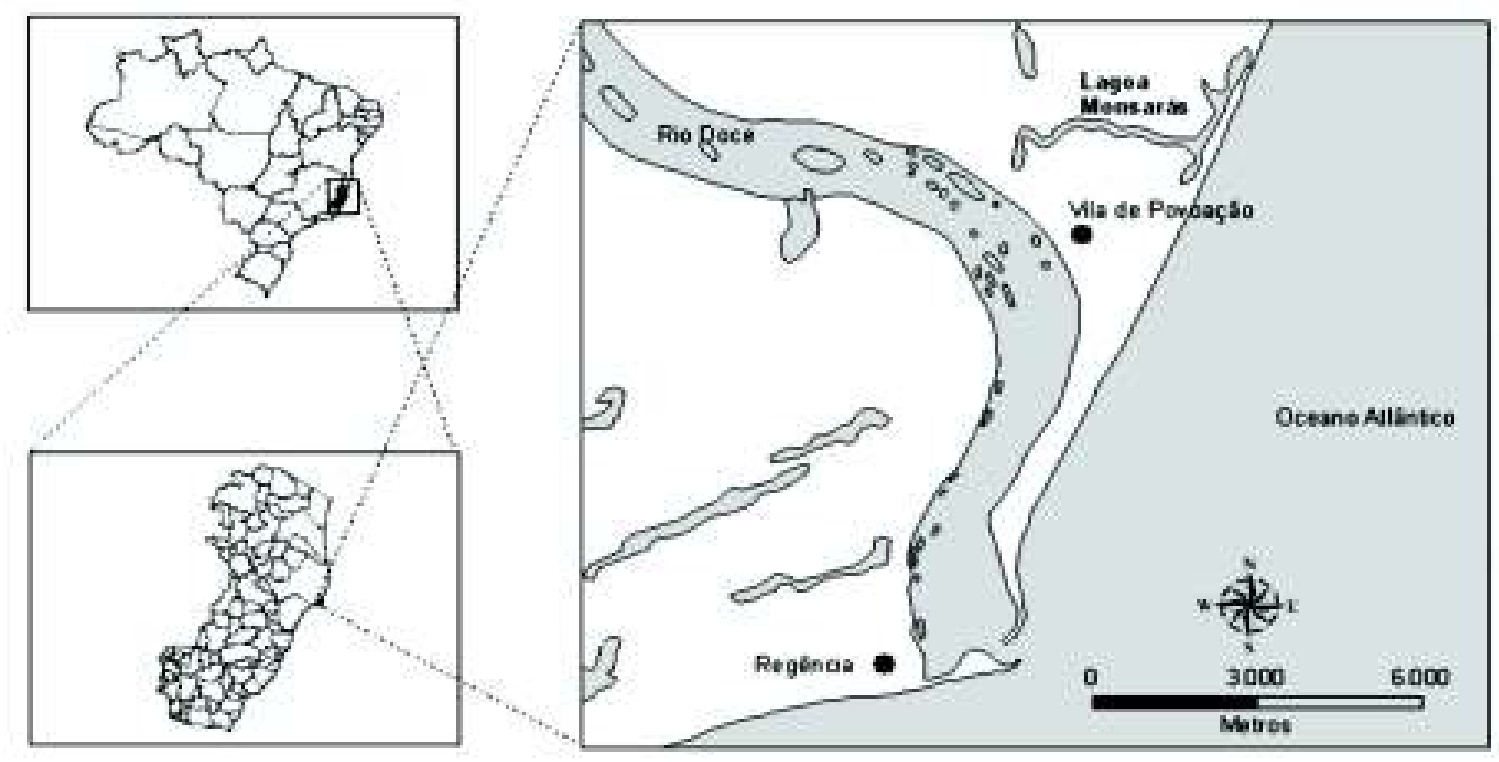

Figura 1 - Localização e mapa da Vila de Povoação, Linhares, ES, e ecossistemas aquáticos estudados entre outubro de 2004 e fevereiro de 2005. 
Tabela 1 - Artes de pesca e principais ecossistemas em que elas são usadas pelos pescadores da Vila de Povoação, Linhares, ES. $\mathrm{n}=$ número de pescarias acompanhadas.

\begin{tabular}{lcccc}
\hline \hline \multicolumn{1}{c}{ Arte de Pesca } & Mar & Rio & Lagoas & $\mathrm{n}$ \\
\hline Arrasto & & & $X$ & 2 \\
Caceia & $\mathrm{X}$ & $\mathrm{X}$ & $\mathrm{X}$ & 2 \\
Jequi & $\mathrm{X}$ & $\mathrm{X}$ & $\mathrm{X}$ & 2 \\
Linha e anzol & & $\mathrm{X}$ & 3 \\
Puçá & $\mathrm{X}$ & $\mathrm{X}$ & $\mathrm{X}$ & 1 \\
Rede de espera & & $\mathrm{X}$ & $\mathrm{X}$ & 3 \\
Rede de mão (calão) & & $\mathrm{X}$ & $\mathrm{X}$ & 1 \\
Tarrafa & & &
\end{tabular}

peixes e camarões de água doce foram identificados segundo Britski et al. (1984) e Mello (2003), respectivamente. Pelo menos um exemplar de cada espécie foi fixado em formalina ( $10 \%$ ) e preservado como testemunha.

\section{RESULTADOS}

\section{Artes Pesqueiras}

A pesca em Povoação é praticada principalmente no leito e ilhas do Rio Doce, no mar e nas lagoas costeiras da região, sendo realizada com oito artes (petrechos) de pesca (Tabela 1). As pescarias, principalmente no mar e rio, são regidas por períodos de safras, onde cada período do ano corresponde a um tipo específico de petrecho para capturar uma espécie-alvo específica. As atividades de pesca são consideradas como comerciais, recreacionais e de subsistência. As capturas comerciais normalmente são vendidas a atravessadores, devido à falta de local para armazenamento.

A pesca comercial é praticada em todos os ecossistemas aquáticos da região, sendo a rede de espera o petrecho de pesca mais utilizado e difundido entre os pescadores profissionais (os outros são o arrasto, o puçá, o jequi e a caceia). Na zona costeira, o seu uso é dependente de águas menos agitadas do verão e vento nordeste, quando os pescadores costumam ficar vários meses alojados em ranchos de palha nas praias. Utilizam uma embarcação própria de 3,5 metros de comprimento, onde 2 ou 3 tripulantes recoIhem a remo o pescado duas vezes ao dia. Cada embarcação costuma armar até 12 panos de redes. Os panos medem aproximadamente 100 metros, possuem malha de $35 \mathrm{~mm}$ a $70 \mathrm{~mm}$ entre os nós opostos e são construidos de linha de 0,40 a 0,70 mm.

Estas pescarias estivais capturam grande quantidade de pescadas (Família Sciaenidae) e também exemplares de cações (Famílias Sphyrnidae e Carcharhynidae) e bagres (Família Ariidae). Segundo os entrevistados, a pesca marinha embarcada em Povoação é uma atividade de grande respeito aos seus praticantes e temida pela maioria da população, pois é realizada somente em barcos a remo que enfrentam grandes ondas e fortes ventos. Existe um conflito entre esta atividade tradicional e a atividade de pesca de arrasto de fundo de barcos de outras regiões, que muitas vezes atropelam e roubam as redes dos moradores locais.

Quando não pescam no mar, os pescadores direcionam seus esforços para os rios e lagoas. Utilizam as mesmas redes que pescam no mar, mais comumente redes de malha de $35 \mathrm{~mm}$ entre os nós opostos, porém, em menor número, de 2 a 9 panos. Utilizam para estas pescarias embarcações menores, botes e canoas, e com um ou dois tripulantes. A pesca em água doce é menos rentável devido à menor captura e ao menor preço do pescado. Esta visa à captura de robalos (Centropomus spp.), traíras (Hoplias malabaricus), carapebas (Eugerres brasilianus) entre outros.

No rio Doce, os pescadores costumam largar suas redes escondidas no meio e nas margens de ilhas, junto à vegetação. Nas lagoas costeiras, as redes geralmente são colocadas de modo a atravessar de uma margem à outra. De fato, a rede de espera é o petrecho mais utilizado nas lagoas, sendo seguida do arrasto e do puçá. Segundo os próprios pescadores, pequenas embarcações motorizadas de pescadores recreacionais de fora da região causam grandes prejuízos ao atropelarem e rasgarem redes dos pescadores locais.

A pesca de arrasto ocorre principalmente na lagoa Monsarás, mas unicamente quando a boca da barra está aberta e a lagoa ligada ao mar, pois o escoamento de água doce deixa-a mais rasa (a lagoa Monsarás é frequentemente aberta manualmente pela comunidade local, visando o desalagamento de lavouras e casas). Esta pescaria utiliza uma canoa a remo e três pessoas e visa ao cerco de cardumes de tainha (Mugil spp.) e carapeba (Eugerres brasilianus). São utilizadas redes de grande extensão, com comprimento entre 100 e 200 metros, linha de $0,40 \mathrm{~mm}$ e malha de $35 \mathrm{~mm}$ entre os nós opostos. Depois de escolhido o local do arrasto, uma pessoa desce da embarcação e posiciona-se dentro d'água, segurando uma ponta da rede perto da margem. Enquanto isso, outro pescador vai remando a canoa e o terceiro soltando a rede, formando um semicírculo ao redor do cardume ou da área visada. Os dois pescadores responsáveis pelas pontas da rede encontram-se na margem da lagoa, e lado a lado, puxam a rede vagarosamente para a margem.

A pesca com puçá é somente praticada em lagoas que periodicamente estão ligadas ao mar. A pesca visa a capturar siris (Callinectes spp.), os quais são consumidos ou comercializados na própria região. Esta pescaria é praticada por homens, mulheres e crianças por ser de simples manuseio. 
No rio Doce, as pescarias mais rentáveis são a de lagosta d'água doce (o Caridae Macrobrachium carcinus) com o jequi, durante o verão, e a de robalo (Centropomus spp.) com a caceia no inverno. O jequi é uma armadilha utilizada para a captura de camarões e lagostas de água doce. Com comprimento entre $1 \mathrm{e}$ 1,5 metros, é de forma cilíndrica (com diâmetro variando de 30 a $50 \mathrm{~cm}$ ), confecçionada manualmente pelos moradores locais que utilizam uma espécie de bambu, corda e arame de aço. Possui uma extremidade aberta, em forma de funil virado para dentro, onde se coloca um atrator (restos de alimentos, carniças e frutas). Para a pesca da lagosta $M$. carcinus, arma-se o jequi em local de corrida d'água, com lastros de pedras e também iscas, onde a lagosta entra atraída por abrigo e alimento. Para a pesca do camarão d'água doce (o Caridae Macrobrachium acanthurus), coloca-se o jequi em um local sem movimento, de água parada. O jequi também é utilizado em lagoas para se armazenar e engordar os siris capturados com puçá.

A caceia é uma longa rede de emalhar, normalmente com malha de $35 \mathrm{~mm}$ entre os nós opostos e $100 \mathrm{~m}$ de comprimento, com uma bóia presa em uma extremidade e uma corda na outra extremidade. O seu manuseio necessita de pelo menos dois pescadores e, quando praticada na lagoa e no rio, utiliza-se também uma embarcação (bote ou canoa). Enquanto um pescador vai guiando a embarcação a remo, o outro vai inicialmente largando a rede, esticando-a e segurando a corda de sua extremidade. Aembarcação então acompanha a rede que deriva ao sabor da corrente do rio, ou guiando-a na lagoa. Após algum tempo ou área percorrida, a rede é recolhida no barco ou na margem. Os peixes que cruzam o caminho da rede ficam emaranhados. Esta pescaria também é praticada no rio Doce com malha grande ( 35 a $70 \mathrm{~mm}$ ) a noite visando o robalo (Centropomus spp.) e com malha miúda (15 a $20 \mathrm{~mm}$ ) de dia visando à captura de manjuba (Família Engraulidae).

A caceia é também praticada no mar mas, neste caso, não se utiliza embarcação. Um pescador, geralmente o mais experiente, dobra a rede e prende-a com um braço. Saindo da areia da praia, o pescador enfrenta as ondas, nadando com o outro braço. Enquanto nada vai aos poucos soltando a rede, esticando-a. Outro pescador vai acompanhando, segurando a corda da outra extremidade da rede. O primeiro sai da água e ambos vão acompanhando a rede que deriva pela ação da corrente longitudinal. Dependendo do comprimento da corda, a rede chega a se afastar centenas de metros da praia. Quando a rede fica pesada ou uma grande distância foi percorrida, a rede é puxada e as capturas recolhidas.

Pescarias recreacional e de subsistência ocorrem em todos os ambientes. Contudo, são menos fre- qüentes que as pescarias profissionais e utilizam menores tamanhos de malha nas redes. No mar são utilizados mais regularmente linha e anzol, rede de emalhar e caceia. Moluscos bivalves (Donax sp.) são coletados na zona de arrebentação da praia. No rio e nas lagoas, os petrechos mais usados são a tarrafa, linha e anzol, rede de mão e puçá.

A pesca de linha e anzol é praticada nos rios e lagoas, principalmente pelos mais jovens como prática de lazer. A pescaria no mar, além de também propiciar lazer, pode ter fins comerciais por que visa espécies grandes de boa aceitação no mercado, como cações (Famílias Carcharhinidae e Sphyrnidae) e pescadas (Família Sciaenidae). Esta pescaria, sem vara, é praticada por pescadores que possuem técnicas próprias para a escolha da isca, o arremesso e a espera do peixe. Muitos pescadores na área marinha, principalmente os profissionais, costumam colocar anzóis na extremidade das redes de espera visando à captura de raias e cações.

A pesca chamada "no canal da beira", utiliza uma rede de espera, presa em uma extremidade por uma âncora e uma bóia e, na outra extremidade, por uma corda que é amarrada na praia. Os pescadores costumam armar a rede no primeiro canal do mar (calha), durante a maré baixa. Utilizam panos de aproximadamente $50 \mathrm{~m}$ de comprimento, linha de 0,40 a $0,60 \mathrm{~mm}$ e malhas de 35 a $70 \mathrm{~mm}$ entre os nós opostos. Eles esticam a rede caminhando dentro d'água e largam a âncora após a primeira zona de arrebentação. Quando a maré sobe, ela estica a rede, presa entre a âncora e a corda amarrada na praia. É neste período que os peixes costumam se emalhar. Os pescadores recolhem as capturas na maré baixa seguinte. Esta técnica é muito utilizada na pesca comercial do robalo, durante o inverno, e pela pesca de subsistência, durante o ano todo.

A pesca de rede de mão com calão é praticada por, no mínimo, dois pescadores. Estes seguram cada extremidade e arrastam a rede pelas margens e partes rasas das lagoas. Utilizam redes com cerca de 10 metros de comprimento, $0,60 \mathrm{~mm}$ de espessura e maIha de 10 a $20 \mathrm{~mm}$ entre os nós opostos. Esta pescaria visa à captura de camarões carídeos (Macrobrachium acanthurus), mas também captura peixes. É intensivamente praticada logo após a abertura da boca da barra da lagoa Monsarás, quando o nível da água abaixa e a densidade de camarões e peixes aumenta, o que facilita a captura.

A tarrafa é utilizada principalmente por pescadores amadores e durante os finais de semana. Pode-se ou não utilizar embarcação a remo (botes ou canoas). A pescaria é essencialmente praticada nas lagoas costeiras por lazer e como fonte de alimento para confraternizações. 


\section{Conhecimento Tradicional}

Segundo os pescadores, as safras mais esperadas são as das pescarias mais rentáveis, como as que visam o robalo (Centropomus spp.) e as pescadas (principalmente Macrodon ancylodon). A pescaria do robalo ocorre nos meses de inverno: "robalo gosta de água ouriçada, de corrida", sendo praticada no rio Doce, no mar e nas lagoas. Todos os entrevistados possuem conhecimentos sobre alguns aspectos da biologia e comportamento do recurso explorado: "os meses de inverno são os meses do robalo porque ele encosta na praia e sobe o rio para desovar". No rio, o robalo é pescado pelas rede de espera e caceia, "sempre de noite". Os pescadores acusam o furão (Centropomus undecimalis) de rasgar as redes: "o furão abre a cara e rasga tudo". O robalo também é pescado no rio e lagoas com currico (atividade de pesca que utiliza iscas artificiais em movimento), mas esta pescaria é pouco praticada pelos nativos da região. "Pegar robalo de rede na lagoa só quando a boca da barra ta aberta". No mar, a pesca de robalo somente é praticada com rede de espera no "canal da beira".

O verão também é um período muito esperado, onde se realiza a pesca no mar, "pesca de fora", para a captura da pescada (várias espécies da Família Sciaenidae). O pescado é recolhido duas vezes ao dia, de manhã e a tarde, quando, segundo os pescadores, normalmente vem mais peixe: "a pescada encosta para desovar e se alimenta de dia, quando o mar tá calmo. A tarde a rede tá cheia". As outras "qualidades" (espécies) capturadas de peixe, também com grande aceitação no mercado, são as sardas (Família Scombridae), os bagres (Família Ariidae) e os cações (Famílias Carcharhinidae e Sphyrnidae): "a sarda encosta em fevereiro, mas rasga tudo, tem que tomar cuidado; os cações são em janeiro. Quando a maré tá cheia e subindo, eles encostam para comer e é até perigoso nadar na praia; os bagres a maioria só pega com rede, porque nessa época eles estão com as crias na boca".

O verão, normalmente época de "cheia do rio" (maior descarga fluvial), é também a época da lagosta d'água doce $M$. carcinus. Segundo os entrevistados, somente os pescadores mais experientes sobem o rio a remo para pescá-las: "pois tem que ser em locais aonde ninguém vai e com correnteza", pois "a lagosta gosta de lugar com movimento".

Os pescadores também relatam os meses preferenciais para a pesca de tainha (Mugil sp.) e manjuba (Família Engraulidae): "a tainha pula mais no mês de agosto"; "de fevereiro a abril, quando o rio começa a baixar, é a época da manjuba e se pesca de dia; se vê o cardume de manjuba antes de lançar a rede". Os mesmos pescadores utilizam seu conhecimento para períodos em que deixam de pescar: "agosto, setembro e outubro são os meses da jamanta (raias da família
Mobulidae). Não pode colocar rede senão elas arrastam e estraga tudo. Época de reprodução dela".

Os pescadores muitas vezes descrevem o comportamento e a atividade dos peixes: "O bagre come $O$ tempo todo", e muitos utilizam até minhocas para pescálos no mar. "No anzol, a raia leva para um lado só, vai descendo. O cação leva para um lado e para o outro, para cima e para baixo". Na boca do rio Doce os pescadores podem detectar as manchas que indicam a presença de um cardume de bagres ("rabo seco", Genidens genidens). Nessas condições, eles costumam não lançar as redes porque os bagres as embolam e machucam as mãos. A lua e o vento, segundo os pescadores, possuem uma influência decisiva nas pescarias: "o peixe a noite fica tudo nas moitas (lagoa Monsarás). Só que a noite clara (lua cheia) eles ficam quietos"; "a lua influencia movimentos dos peixes (pescada), às vezes na lua nova eles se mexem mais de noite e caem mais a noite também"; "a lua minguante trás tempo ruim, vento sul. A gente já se prepara para qualquer hora tirar as redes"; "vento norte é bom para pesca de linha de mão".

Uma síntese do conhecimento dos pescadores sobre as principais espécies alvo e petrechos utilizados é apresentada na tabela 2.

\section{Capturas}

Compuseram as capturas das diferentes artes de pesca e ecossistemas da região 63 espécies de peixes referentes a 27 famílias e 10 ordens (Tabela 3 ). A arte de pesca que envolveu maior número de espécies foi a rede de espera, seguida da rede de mão com calão. A maior riqueza foi encontrada na lagoa Monsarás, com 45 espécies, seguido da área marítima, com 19, e as desembocaduras do rio Doce e da lagoa Monsarás (Foz) com 5 espécies. Somente Genidens genidens foi capturada em todos os ambientes. Engraulis anchoita, Polydactylus virginicus e Mugil $\mathrm{sp}$. foram capturadas em dois dos três ambientes (Tabela 3).

\section{DISCUSSÃO}

A grande diversidade de pescarias praticadas pelos pescadores e a comunidade de Povoação é fruto, portanto, do enorme conhecimento sobre a dinâmica dos recursos que eles exploram. Os pescadores artesanais de Povoação, assim como de outras áreas do Brasil, possuem conhecimento detalhado sobre o comportamento, a reprodução, a alimentação e a migração dos peixes, o qual é utilizado nas estratégias de pesca (Mourão \& Nordi, 2003; Souza \& Barrella, 2001). Seu conhecimento é provavelmente baseado em experiências próprias, no sucesso das pescarias, e no 
Tabela 2 - Síntese do conhecimento tradicional dos pescadores de Povoação a respeito dos principais recursos explorados, sazonalidade, habitats, comportamentos e petrechos utilizados.

\begin{tabular}{|c|c|c|c|c|}
\hline Recurso & Sazonalidade & Habitat & Comportamento & Petrechos envolvidos \\
\hline Robalo (Centropomus spp.) & Inverno & Mar, rio e lagoas ligadas ao mar & $\begin{array}{l}\text { Habita águas de corrida; encosta para } \\
\text { desovar; pescado a noite }\end{array}$ & Rede de espera; caceia; currico \\
\hline Pescadas (Sciaenidae) & Verão & Mar & $\begin{array}{l}\text { Alimenta-se a tarde (período de maior } \\
\text { captura); verão é época de reprodução }\end{array}$ & Rede de espera; anzol; caceia \\
\hline Cações (Carcharhinidae e Sphyrnidae) & Janeiro & Mar & $\begin{array}{l}\text { Encostam para comer com a subida da } \\
\text { maré }\end{array}$ & Rede de espera; anzol \\
\hline Bagres (Ariidae) & Verão & Mar, rio, lagoas & $\begin{array}{l}\text { Guardam filhote na boca; nadam em } \\
\text { cardume; comem de tudo }\end{array}$ & Rede de espera; anzol; caceia \\
\hline $\begin{array}{l}\text { Lagosta de água doca (Macrobrachium } \\
\text { carcinus) }\end{array}$ & Verão (período de cheia do rio) & Rio & Gostam de correnteza & Jequi \\
\hline $\begin{array}{l}\text { Camarão de água doce (Macrobrachium } \\
\text { acanthurus) }\end{array}$ & Ano inteiro & $\begin{array}{l}\text { Rio e lagoas (principalmente após } \\
\text { abertura) }\end{array}$ & Gostam de água parada & Jequi \\
\hline Manjuba (Engraulidae) & Entre fevereiro e abril & Rio & Nadam em cardume junto à superfície & Caceia \\
\hline Jamanta (Mobulidae) & Entre agosto e outubro & Mar & Encostam para reprodução & Rede de espera (não alvo) \\
\hline
\end{tabular}

conhecimento acumulado de seus pais, avós e companheiros de pesca (Mackinson \& Nottestad, 1998).

A cada época do ano os pescadores utilizam técnicas e petrechos que visam a captura de espécies alvo distintas, em diferentes ambientes e ecossistemas. Cada técnica e petrecho utilizado influencia a composição da fauna de peixes capturados. Segundo Camargo \& Petrere (2001), o estoque pescado é diretamente ligado ao padrão espacial de exploração dos recursos. Com base nesta afirmativa concluise que os pescadores de Povoação são obrigados a pescar nos diferentes habitats nas distintas épocas do ano. Esta prática de rodízio, onde os pescadores praticam pescarias rotativas ao longo do ano, é imposta, segundo eles, por fatores ambientais (ventos, fortes ondas, nível do rio, etc) e biológicos ou comportamentais (por exemplo, a migração reprodutiva), e, assim, também forma a base de seus conhecimentos. Contudo, como todos os pescadores do mundo, é provável que os pescadores de Povoação utilizem todo seu conhecimento e vivência para otimizar as capturas e minimizar os seus esforços (Mackinson \& Nottestad, 1998).

Em muitos lugares, a intensa pressão da pesca já tem levado à redução dos tamanhos médios dos peixes e a mudanças na composição do pescado (Albaret \& Lae, 2003). Em Povoação, apesar das pescarias serem tradicionais e praticadas em rodízio ao longo do ano, algumas características levantam questionamentos quanto à sustentabilidade das capturas. Constatamos: 1) a existência de atividades de pesca comercial em períodos de reprodução (robalo, pescada, bagre, jamanta), 2) a utilização de malhas menores nas redes empregadas em pescarias recreacionais, 3) o conflito existente em relação à pesca de arrasto com portas, realizada há muitos anos na costa norte da foz do rio Doce e 4) a prática de abertura da boca da barra da lagoa Monsarás para a manutenção do baixo nível d'água.

Entretanto, as próprias informações dos pescadores, apresentadas neste estudo, podem auxiliar um manejo das espécies envolvidas e das áreas sensíveis nos períodos de reprodução. A regulação e manejo das atividades poderiam iniciar-se com o controle do núme- ro e do tamanho das malhas das redes, assim como do esforço de pesca e do tamanho mínimo de espécies alvo durante os períodos de reprodução (Cowx \& Gerdeaux, 2004). Os resultados deste estudo incentivam ao desenvolvimento de estudos biológicos e pesqueiros, a fim de ordenar as atividades quanto à sustentabilidade das capturas.

Na região de Povoação, somente o robalo (Centropomus spp.) possui um tipo de manejo em sua época de reprodução baseado em um acordo informal entre fiscalizadores e pescadores locais ( $N$. Leite, comunicação pessoal). Durante os meses de maio a juIho, os pescadores pescam somente 15 dias consecutivos por mês, deixando os outros 15 dias resguardados para o peixe subir os corpos de água doce para desovar. Também, entre novembro e fevereiro, é o período da piracema, onde é proibida a pesca de quaisquer espécies de água doce. Contudo, não existe regulação para os diferentes petrechos utilizados ao longo de todo o ano, nem uma regulação efetiva para os tamanhos das malhas utilizadas. As atividades realizadas no mar, por não serem fiscalizadas, são alvo de conflitos entre pescarias tradicionais (locais) com pescarias industriais (de outras áreas, não de Povoação).

Baseado nas atividades desenvolvidas em Povoação, educação ambiental, alternativas de valorização do pescado e a participação de todos os envolvidos são facetas do manejo a serem desenvolvidas na região. Assim, a comunidade local deve ser preparada para um futuro engajamento na proteção e no manejo do ambiente que ela explora (Barros et al., 2000).

Os ambientes explorados pelos pescadores de Povoação, provavelmente devido à influência de águas dulcícolas e marinhas, abrigam grande quantidade de espécies. Segundo Poizat et al. (2004), muitas espécies de peixes passam parte do seu ciclo de vida em regiões estuarinas, nas quais encontram condições para crescimento, reprodução ou alimentação. As pescarias, com isso, deveriam ser praticadas com malhas maiores, pois estas aumentam o potencial de seleção das atividades (Vooren, 1983), diminuindo um possível impacto indesejado, sobretudo de fases iniciais quando em áreas de criadouro. O manejo da pesca 
Tabela 3 - Lista de espécies (alvo, não-alvo, by catch e rejeito), habitat e petrechos relacionados aos peixes capturados em Povoação entre Outubro 2004 e Março 2005.

\begin{tabular}{|c|c|c|c|c|c|c|c|c|}
\hline Ordem/Família/Espécie & $\mathrm{H}$ & $\mathrm{P}$ & Ordem/Família/Espécie & $\mathrm{H}$ & $\mathrm{P}$ & Ordem/Família/Espécie & 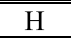 & $\mathrm{P}$ \\
\hline Carcharhiniformes & & & Heptapteridae & & & Macrodon ancylodon (Bloch e Schneider, 1801) & $\mathrm{M}$ & $\mathrm{Re} ; \mathrm{Ca}$ \\
\hline Carcharhinidae & & & Rhamdia quelen (Quoy e Gaimard, 1824) & $\mathrm{L}$ & $\mathrm{Rc}$ & Menticirrhus americanus (Linnaeus, 1758) & M & $\operatorname{Re}$ \\
\hline Rhizoprionodon porosus $($ Poey, 1861) & M & $\mathrm{Re} ; \mathrm{La}$ & Beloniformes & & & Micropogonias furnieri (Desmarest, 1823) & $\mathrm{L}$ & $\mathrm{Ar}$ \\
\hline Sphyrnidae & & & Belonidae & & & Nebris microps (Cuvier, 1830) & M & $\operatorname{Re}$ \\
\hline Sphyrna tudes (Valenciennes, 1822) & $\mathrm{M}$ & $\mathrm{Re} ; \mathrm{La}$ & Strongylura tiтиси (Walbaum, 1792) & $\mathrm{L}$ & $\mathrm{Ar}$ & Paralonchurus brasiliensis (Steindachner, 1875) & M & $\operatorname{Re}$ \\
\hline Elopiformes & & & Hemiramphidae & & & Stellifer brasiliensis (Schultz, 1945) & $\mathrm{L}$ & $\operatorname{Re}$ \\
\hline Elopidae & & & Hyporhamphus roberti (Valenciennes, 1847) & $\mathrm{L}$ & Ar; Rc & Stellifer rastrifer (Jordan, 1889) & M & $\operatorname{Re}$ \\
\hline Elops saurus (Linnaeus, 1766) & $\mathrm{F}$ & $\mathrm{Re} ; \mathrm{Ca}$ & Syngnathiformes & & & Polynemidae & & \\
\hline Clupeiformes & & & Syngnathidae & & & Polydactylus virginicus (Linnaeus, 1758) & $\mathrm{M} ; \mathrm{L}$ & $\operatorname{Re}$ \\
\hline Engraulidae & & & Microphis $\mathrm{cf}$ lineatus (Kaup, 1856) & $\mathrm{L}$ & $\mathrm{Rc}$ & Mugilidae & & \\
\hline Anchoa spinifer (Valenciennes, 1848) & $\mathrm{M}$ & $\operatorname{Re}$ & Perciformes & & & Mugil curema (Valenciennes, 1836) & $\mathrm{F}$ & $\mathrm{Ca} ; \mathrm{Ta}$ \\
\hline Anchovia clupeoides (Swainson, 1839) & $\mathrm{L}$ & $\mathrm{Rc}$ & Centropomidae & & & Mugil gaimardianus (Desmarest, 1831) & $\mathrm{L}$ & $\mathrm{Rc}$ \\
\hline Anchoviella lepidentostole (Fowler, 1911) & $\mathrm{L}$ & $\mathrm{Rc}$ & Centropomus ensiferus (Poey, 1860) & $\mathrm{L}$ & $\mathrm{Rc}$ & Mugil incilis (Hancock, 1830) & $\mathrm{L}$ & $\mathrm{Ca}$ \\
\hline Engraulis anchoita (Hubbs e Marini, 1935) & $\mathrm{M} ; \mathrm{L}$ & $\mathrm{Re} ; \mathrm{Rc}$ & Centropomus mexicanus (Bocourt, 1868) & $\mathrm{L}$ & $\mathrm{Rc}$ & Mugil sp. & $\mathrm{F} ; \mathrm{L}$ & $\mathrm{Rc}$ \\
\hline Lycengraulis grossidens (Agassiz, 1829) & $\mathrm{L}$ & $\operatorname{Re}$ & Centropomus parallelus $(\mathrm{Poey}, 1860)$ & $\mathrm{L}$ & $\mathrm{Re} ; \mathrm{Ca} ; \mathrm{Rc}$ & Cichlidae & & \\
\hline Characiformes & & & Centropomus pectinatus (Poey, 1860) & $\mathrm{L}$ & $\mathrm{Rc}$ & Cichla ocellaris (Bloch \& Schneider, 1801) & $\mathrm{L}$ & $\mathrm{Rc}$ \\
\hline Erythrinidae & & & Centropomus undecimalis (Bloch, 1792) & $\mathrm{F} ; \mathrm{L}$ & $\mathrm{Re} ; \mathrm{Ca} ; \mathrm{Rc}$ & Geophagus brasiliensis (Quoy \& Gaimard, 1824) & $\mathrm{L}$ & $\mathrm{Rc}$ \\
\hline Hoplerythrinus unitaeniatus (Spix e Agassiz, 1829) & $\mathrm{L}$ & $\mathrm{Rc}$ & Carangidae & & & Oreochromis niloticus (Linnaeus, 1758) & $\mathrm{L}$ & $\mathrm{Rc}$ \\
\hline Hoplias malabaricus (Bloch, 1794) & $\mathrm{L}$ & $\mathrm{Re} ; \mathrm{La}$ & Caranx hippos (Linnaeus, 1766) & $\mathrm{L}$ & $\operatorname{Re}$ & Eleotridae & & \\
\hline Characidae & & & Caranx latus (Agassiz, 1831) & $\mathrm{L}$ & $\mathrm{Re} ; \mathrm{Rc}$ & Eleotris pisonis (Gmelin, 1789) & $\mathrm{L}$ & $\mathrm{Rc}$ \\
\hline Astyanax bimaculatus (Linnaeus, 1758) & $\mathrm{L}$ & $\mathrm{Rc}$ & Oligoplites palometa (Cuvier, 1833) & $\mathrm{L}$ & $\mathrm{Re}$ & Gobiidae & & \\
\hline Pygocentrus nattereri (Kner, 1858) & $\mathrm{L}$ & $\mathrm{Rc}$ & Oligoplites saurus (Bloch e Schneider, 1801) & $\mathrm{L}$ & $\mathrm{Rc}$ & Gobionellus oceanicus (Pallas, 1770) & $\mathrm{L}$ & $\mathrm{Rc}$ \\
\hline Prochilodontidae & & & Selene vomer (Linnaeus, 1758) & $\mathrm{L}$ & $\mathrm{Ar}$ & Ephippidae & & \\
\hline Prochilodus sp. & $\mathrm{L}$ & $\mathrm{Re} ; \mathrm{Rc}$ & Lutjanidae & & & Chaetodipterus faber (Broussonet, 1782) & M & $\operatorname{Re}$ \\
\hline Siluriformes & & & Lutjanus cyanopterus (Cuvier, 1828) & $\mathrm{L}$ & $\operatorname{Re}$ & Stromateidae & & \\
\hline Clariidae & & & Gerreidae & & & Peprilus paru (Linnaeus, 1758) & M & $\operatorname{Re}$ \\
\hline Clarias gariepinus (Burchell, 1822) & $\mathrm{L}$ & $\mathrm{Re} ; \mathrm{La}$ & Diapterus rhombeus (Cuvier, 1829) & $\mathrm{L}$ & $\operatorname{Re} ; \mathrm{Ar}$ & Pleuronectiformes & & \\
\hline Ariidae & & & Eucinostomus lefroyi (Goode, 1874) & $\mathrm{L}$ & $\mathrm{Re} ; \mathrm{Rc}$ & Paralichthydae & & \\
\hline Cathorops spixii (Agassiz, 1829) & M & $\mathrm{Re} ; \mathrm{La}$ & Eugerres brasilianus (Cuvier, 1830) & $\mathrm{L}$ & $\mathrm{Re} ; \mathrm{Ar}$ & Citharichthys arenaceus (Evermann e Marsh, 1902) & $\mathrm{L}$ & $\mathrm{Rc}$ \\
\hline Genidens genidens (Valenciennes, 1839) & $\mathrm{M} ; \mathrm{F} ; \mathrm{L}$ & $\mathrm{La} ; \mathrm{Rc} ; \mathrm{Ta}$ & Haemulidae & & & Citharichthys spilopterus (Gunther, 1862) & $\mathrm{L}$ & $\mathrm{Rc}$ \\
\hline Bagre bagre (Linnaeus, 1766) & $\mathrm{M}$ & Re; La & Conodon nobilis (Linnaeus, 1758) & $\mathrm{M}$ & $\mathrm{Re} ; \mathrm{La}$ & Achiriidae & & \\
\hline Auchenipteridae & & & Sciaenidae & & & Achirus declivis (Chabanaud, 1940) & M & $\operatorname{Re}$ \\
\hline Trachelyopterus galeatus (Linnaeus, 1766) & $\mathrm{L}$ & $\mathrm{Re} ; \mathrm{Rc}$ & Bairdiella ronchus (Cuvier, 1830) & $\mathrm{L}$ & $\operatorname{Re}$ & Tetraodontiformes & & \\
\hline $\begin{array}{l}\text { Callichthyidae } \\
\text { C. }\end{array}$ & & & Cynoscion virescens (Cuvier,1830) & $\mathrm{M}$ & $\operatorname{Re}$ & Tetraodontidae & & \\
\hline Hoplosternum littorale (Hancock, 1828) & $\mathrm{L}$ & $\mathrm{Re} ; \mathrm{Rc}$ & Larimus breviceps (Cuvier, 1830) & M & $\mathrm{Re}$ & Sphoeroides testudineus (Linnaeus, 1758) & $\mathrm{L}$ & $\mathrm{Rc}$ \\
\hline
\end{tabular}

Hoplosternum littorale (Hancock 1828$)$

$\mathrm{Re} ; \mathrm{Rc} \quad$ Larimus breviceps (Cuvier, 1830)

$\begin{array}{lll}\mathrm{M} & \mathrm{Re} & \text { Tetraodontidae } \\ \mathrm{M} & \mathrm{Re} & \text { Sphoeroides testudineus (Linnaeus, } 1758\end{array}$ 
recreacional também é de muita importância, pois a falta deste controle pode trazer problemas para a composição dos estoques explotados (Bninsk \& Wolos, 2001), principalmente devido a captura de indivíduos juvenis (H.T. Pinheiro, observação pessoal). Este manejo, por envolver grande parte da comunidade local, deve ser bem fundamentado e abordado com cautela, sendo subsidiado por atividades de educação ambiental e a participação da comunidade.

Somado à dificuldade do manejo, influenciada pela cultura, tradição e petrechos dos pescadores locais, Povoação enfrenta um crescimento populacional associado a um desenvolvimento industrial e uma provável pavimentação da estrada de acesso ao vilarejo, com ligação a um grande centro urbano. Adams (2000) afirma que a questão demográfica influencia diretamente no impacto causado sobre os ecossistemas. O processo de crescimento desordenado pode acelerar uma demanda insustentável por recursos naturais.

Uma mudança de paradigma envolve uma adaptação do manejo tradicional dos recursos para um manejo integrado dos ecossistemas e, portanto, condiz com o aumento da comunicação e dos programas de educação ambiental sobre a proteção e a conservação das águas (Cowx \& Gerdeaux, 2004). Além disso, segundo Vega-Cendejas \& Santillana (2004), o manejo dos sistemas estuarinos requer a proteção dos habitats críticos para as espécies dependentes e residentes. A freqüência regular e o rápido escoamento pela abertura proposital da lagoa costeira resultam com que muitos peixes residentes e todo seu micro-habitat acabem morrendo (H.T. Pinheiro, observação pessoal). A proteção de certos tipos de habitats surge como mais uma alternativa para a sobrevivência em longo prazo e contínua produtividade das espécies.

O estabelecimento de reservas (áreas protegidas e áreas de uso sustentável) e um incremento nos esforços de educação e proteção também podem levar a um aumento na abundância e no tamanho médio dos peixes e à reabilitação da comunidade marinha, e assim colaborar contra o colapso das pescarias e da cultura local.

\section{AGRADECIMENTOS}

Este trabalho beneficiou-se da imensa experiência ictiológica de João Luiz Gasparini (UFES) e José Luiz Helmer (FAESA), colaboração de Hélio dos Santos Sá (UFES), do apoio logístico de Agnaldo Silva Martins (UFES) e de um extenso estágio para a proteção das tartarugas marinhas, na base do Projeto TAMAR em Povoação. Agradecemos a Tonim e Rogério (Projeto TAMAR), assim como os pescadores Manuel, Chico, Cadu, Schimith, Bitelo, Jossi, Jorge, Getulio, Simião e todos os outros que contribuíram com seus conhecimentos.

\section{REFERENCIAS}

Adams, C. 2000. As populações caiçaras e o mito do bom selvagem: a necessidade de uma nova abordagem interdisciplinar. Revista de Antropologia, 43 (1): 145-182.

Albaret, J.J. \& Lae, R. 2003. Impact of fishing on fish assemblages in tropical lagoons: the example of the Ebrie lagoons, West Africa. Aquatic Living Resources, 16: 1-9.

Barros, H.M.; Eskinazi-Leça, E. \& Paranaguá, M.U. 2000. The disappearing fish: an understanding of sustainability among estuarine fishermen communities of Bragança, PA. Aquatic Ecosystem Health and Management, 3: 553-560.

Bazairi, H.; Bayed, A.; Glémarec, M. \& Hily, C. 2003. Spatial organization of macrozoobenthic communities in response to environmental factors in a coastal lagoon of the NW African coast (Merja Zerca, Morocco). Oceanologica Acta, 26: 457-471.

Bninsk, M. \& Wolos, A. 2001. Management of selected Polish commercial and recreational lake fisheries activities. Fisheries Management and Ecology, 8: 333-343.

Boffo, M.S. \& Reis, E.G. 2003. Atividade pesqueira da frota de media escala no extremo sul do Brasil. Atlântica, Rio Grande, 25 (2): 171:178.

Britski, H.A.; Sato, Y. \& Rosa, A.B.S. 1984. Manual de identificação de peixes da região de Três Marias, com chaves de identificação para os peixes da bacia do São Francisco. Brasília, Câmara dos deputados \& CODEVASF. $143 \mathrm{p}$.

Camargo, S.A.F. \& Petrere Jr., M. 2001. Social and financial aspects of the artesan fisheries of middle São Francisco River, Minas Gerais, Brazil. Fisheries Management and Ecology, 8: 163-171.

Chaves, P.; Pichler, H. \& Robert, M. 2002. Biological, technical and socioeconomic aspects of the fishing activity in a Brazilian estuary. Journal of Fish Biology, 61: 52-59.

Cowx, I.G. \& Gerdeaux, D. 2004. The effects of fisheries management practices on freshwater ecosystems. Fisheries Management and Ecology, 11: 145-151.

Figueiredo, J.L. 1977. Manual de peixes marinhos do sudeste do Brasil. I. Introdução. Cações, raias e quimeras. Museu de Zoologia da Universidade de São Paulo, São Paulo, 104 p

Figueiredo, J.L. \& Menezes, N.A. 1978. Manual de peixes marinhos do sudeste do Brasil. II. Teleostei (1). Museu de Zoologia da Universidade de São Paulo, São Paulo, 110 p. 
Figueiredo, J.L. \& Menezes, N.A. 1980. Manual de peixes marinhos do sudeste do Brasil. III. Teleostei (2). Museu de Zoologia da Universidade de São Paulo, São Paulo, 90 p.

Figueiredo, J.L. \& Menezes, N.A. 2000. Manual de peixes marinhos do sudeste do Brasil. VI. Teleostei (5). Museu de Zoologia da Universidade de São Paulo, São Paulo, 116 p.

Fischer, W. 1978. FAO Species identification sheets for fishery purposes. West Atlantic (Fishing Area 31). Vols 1-5. FAO, Rome.

Mackinson, S. \& Nottestad, L. 1998. Combining local and scientific knowledge. Reviews in Fish Biology and Fisheries, 8: 481-490.

Mello, G. A. S. (Ed.) 2003. Manual de identificação dos Crustacea Decapoda de água doce do Brasil. São Paulo, Universidade de São Paulo, 429 p.

Menezes, N.A. \& Figueiredo, J.L. 1980. Manual de peixes marinhos do sudeste do Brasil. IV. Teleostei (3). Museu de Zoologia da Universidade de São Paulo, São Paulo, 96 p.

Menezes, N.A. \& Figueiredo, J.L. 1985. Manual de peixes marinhos do sudeste do Brasil. V. Teleostei (4). Museu de Zoologia da Universidade de São Paulo, São Paulo, 105 p.

Mourão, J.S. \& Nordi, N. 2003. Etnoictiologia de pescadores artesanais do estuário do rio Mamanguape, Paraíba, Brasil. Boletim do Instituto de Pesca de São Paulo, 29 (1): 9-17.

Poizat, G.; Rosecchi, E.; Chauvelon, P.; Contourneti, P. \& Crivelli, A.J. 2004. Long-term fish and macro- crustacean community variation in a Mediterranean lagoon. Estuarine, Coastal and Shelf Science, 59: 615-624.

Rogers, C.S. \& Beets, J. 2001. Degradation of marine ecosystems and decline of fishery resouces in marine protected areas in Virgin Islands. Environmental Conservation, 28 (1): 312-322.

Rueda, M. \& Defeo, O. 2003. Linking fishery management and conservation in a tropical estuarine lagoon: biological and physical effects of an artisanal fishing gear. Estuarine, Coastal and Shelf Science, 56: 935-942.

Schmid, C.; Schafer, H.; Podesta, G. \& Zenk, W. 1995. The Vitória Eddy and it's relation to the Brazil Current. Journal of Physical Oceanography, 25: 2532-2546.

Souza, M.R. \& Barrella, W.B. 2001. Conhecimento popular sobre peixes numa comunidade caiçara da estação ecológica da Juréia, Itatins/SP. Boletim do Instituto de Pesca de São Paulo, 27 (2), 123-130.

Vega-Cendejas, M.E. \& Santillana, M.H. 2004. Fish Community structure and dynamics in a coastal hypersalina lagoon: Rio Lagartos, Yucatan, México. Estuarine, Coastal and Shelf Science, 60: 285299.

Vooren, C.M. 1983. Seleção pela malha na pesca de arrasto da castanha Umbrina canosai, pescada Cynoscion striatus e pescadinha Macrodon ancylodon no Rio Grande do Sul. Documentos Técnicos 04 Oceanografia. Universidade do Rio Grande, Rio Grande, RS, Brasil. 